\title{
STRUCTURE OF THE VASCULITIDES OBSERVED IN THE CLINIC OF RHEUMATOLOGY - SOFIA
}

\author{
Tsv. Yoneva, Y. Zdravkova, G. Kotov, R. Rashkov, I. Sheytanov
}

Clinic of Rheumatology, UMHAT "Sv. Ivan Rilski", Department of Rheumatology, Medical University - Sofia

\begin{abstract}
Systemic vasculitides are a heterogenic group of disorders characterized by destructive inflammation and fibrinoid necrosis of the vascular wall, vessel occlusion and tissue ischemia. Vasculitides presenting with necrosis are included in none of the contemporary classifications, even though this type of vascular pathology is the one with the most dramatic manifestations in rheumatology. There have been no analyses of the nosological association, clinical features and therapeutic management of the vasculitides with necrosis in the pertinent literature. The aim of the present study was to analyze vasculitides in the Bulgarian population in terms of their nosological association; to examine the portion that ANCA-associated vasculitides represent out of all vasculitic syndromes on the one hand, and to make an analysis of the vasculitides with necrosis according to their nosological association on the other. In the present study, we included 388 patients with vasculitis, 251 of whom were female and 137 male. We conducted a prospective and retrospective analysis which covered the patients with vasculitis who were admitted to the Clinic of Rheumatology over the period 2009-2018. ANCA-associated vasculitides were the most often diagnosed vasculitides in the Clinic of Rheumatology. Vasculitic manifestations over the course of connective tissue diseases (most often systemic lupus erythematosus and systemic sclerosis) were the second most common group. Life-threatening cases of vasculitis with necrosis were mainly the result of flares of different connective tissue diseases. The major necrotizing vasculitides (Wegener's granulomatosis and microscopic polyangiitis) were responsible for $12.6 \%$ of the cases of vasculitis with necrosis. In order to establish the correct diagnosis and start the suitable treatment, it is of vital importance to recognize the different vasculitic syndromes and their wide differential diagnosis. Most of them respond well to the currently available therapeutic options, especially if the correct diagnosis has been established early.
\end{abstract}

Key words: Vasculitis, ANCA-associated vasculitides (AAV), vasculitis with necrosis, classification

\section{INTRODUCTION}

The term 'vasculitis' or 'angiitis' refers to multiple diseases which are characterized by inflammation of the vascular wall and subsequent tissue or organ damage [1,2]. Systemic vasculitides are a heterogenic group of disorders characterized by destructive inflammation and fibrinoid necrosis of the vascular wall, vessel occlusion and tissue ischemia. The clinical manifestations depend on the type and size of the damaged vessels [3]. Vasculitides may be idiopathic, primary or secondary to another disease such as systemic lupus erythematosus (SLE) and rheumatoid arthritis (RA) or related to infections, medications or toxic agents [3, 4]. The clinical features depend on the type, size and localization of the damaged vessels and may vary from benign and limited (such as cutaneous vasculitis) to life-threatening systemic vasculitides (e.g. pulmonary-renal syndrome in microscopic polyangiitis). Different features which may be used to classify the vasculitides include etiology, pathogenesis, type and size of the involved vessels, type of inflammatory process, target organ damage, clinical manifestations, genetic predisposition, demographic characteristics (age, sex, race, geographic distribution). Currently, there is no unified classification of the vasculitides, which can be explained by their significant diversity and, to a large extent, the lack of anatomopathological specificity, of sufficient knowledge regarding their pathogenesis and the overlapping clinical manifestations of vasculitides and other systemic diseases [1]. The contemporary classification of vasculitides follows the nomenclature introduced by the Chapel Hill Consensus Conference ( $\mathrm{CHCC}$ ) in 1994, subsequently revised by CHCC in 2012. The vasculitic syndromes were divided into three groups and were further classified into three sections - Large Vessel Vasculitis (LVV), Medium Vessel Vasculitis (MVV) and Small Vessel Vasculitis (SVV), to which new categories have been added [5]. 
Table 1. Nomenclature of vasculitides according to CHCC

\begin{tabular}{|l|}
\hline Large vessel vasculitis (LVV) \\
Takayasu arteritis (TAK) \\
Giant cell arteritis (GCA) \\
\hline Medium vessel vasculitis (MVV) \\
Polyarteritis nodosa (PAN) \\
Kawasaki disease(KD) \\
\hline Small vessel vasculitis (SVV) \\
ANCA associated vasculitis(AAV) \\
Microscopic polyangiitis (MPA) \\
Granulomatosis with polyangiitis (Wegener's granulomatosis) (GPA) \\
Eosinophilic granulomatosis with polyangiitis (Churg-Strauss syndrome) (EGPA) \\
Immune complex SVV \\
Anti-glomerular basement membrane (anti-GBM) disease \\
Cryoglobulinemic vasculitis (CV) \\
IgA vasculitis (Henoch-Schönlein) (IgAV) \\
Hypocomplementemic urticarial vasculitis (HUV) (anti-C1) \\
\hline Variable vessel vasculitis (VVV) \\
Behçet's disease (BD) \\
Cogan's syndrome (CS) \\
\hline Single-organ vasculitis (SOV) \\
Cutaneous leukocytoclastic angiitis \\
Cutaneous arteritis \\
Primary central nervous system vasculitis \\
Isolated aortitis \\
Others \\
\hline Vasculitis associated with systemic disease \\
Lupus vasculitis \\
Rheumatoid vasculitis \\
Sarcoid vasculitis \\
Others \\
Vasculitis associated with probable etiology \\
Hepatitis C virus-associated cryoglobulinemic vasculitis \\
Hepatitis B virus-associated vasculitis \\
Syphilis-associated vasculitis \\
Drug-associated immune complex vasculitis \\
Drug-associated ANCA-associated vasculitis \\
Others \\
\hline
\end{tabular}

ANCA-associated vasculitides (AAV) are multisystemic autoimmune disorders characterized by necrotizing inflammation of small vessels, production of antibodies against antigens in the cytoplasm of neutrophils (ANCA) and variable organ manifestations $[6,7,8]$. They include the following vasculitides: Granulomatosis with polyangiitis (Wegener's granulomatosis) (GPA, WG), Microscopic polyangiitis (MPA), Eosinophilic granulomatosis with polyangiitis (Churg-Strauss syndrome) (EGPA, CSS). Their histological features are those of necrotic focal vasculitis of small vessels; in the case of GPA and EGPA, there are also granulomatous lesions. AAV are also called "pauci-immune" due to the fact that immunoglobulins and complement components are not present in the vasculitic lesions [9].
The vasculitides are diseases which present with variable clinical manifestations. Some of them present with features indicating systemic involvement - skin rash, peripheral neuropathy, arthritis, internal organ symptoms - lungs, kidneys, gastrointestinal tract, heart, etc. Other vasculitides present with isolated organ damage - skin, peripheral nerves or individual internal organs. On the other hand, small vessel vasculitides, which initially present with mild and often inconspicuous clinical manifestations, have different prognosis and require different therapy, e.g. the prognosis in patients with Henoch-Schönlein purpura is favorable, while in patients with purpura caused by microscopic polyangiitis the condition may progress to a life-threatening one if not managed with immunosuppressives [11].The most acute and dangerous clinical manifestation of vascular conflict is necrosis. Based on the presence or absence of necrotic lesions on the skin and/or in internal organs, vasculitides may be divided into two groups - vasculitis with necrosis (VN) and vasculitis without necrosis $(\mathrm{V})$. Vasculitides presenting with necrosis are included in neither of the contemporary classifications, even though this type of vascular pathology is the one with the most dramatic manifestations in rheumatology.

Necrotizing vasculitis and VN. Necrotizing vasculitis is a histological diagnosis characterized by segmental inflammation in all layers of the wall of medium and small muscular arteries. Specific features of the inflammation include fibrinoid necrosis and cellular infiltration (polymorphonuclear cells in the acute stage and mononuclear cells in the disease's subacute and chronic stage). The most typical representatives of necrotizing vasculitis are PAN and AAV. VN is a clinical diagnosis characterized by the presence of necrotic lesions on the limbs and/or in the internal organs. There have been no analyses of the nosological association, clinical features and therapeutic management of the $\mathrm{VN}$ in the pertinent literature. Only separate cases of $\mathrm{VN}$ have been described. At present, it is unclear what distinguishes these patients from patients with other types of vascular pathology.

The aim of the present study was to analyze vasculitides in the Bulgarian population in terms of their nosological association; to examine the portion that AAV represent out of all vasculitic syndromes on the one hand, and to make an analysis of the $\mathrm{VN}$ according to their nosological association on the other. 


\section{MATERIAL AND METHODS}

Patients. In the present study, we included 388 patients with vasculitis, 251 of whom were female and 137 male. The patients were diagnosed and treated in the Clinic of Rheumatology at UMHAT „Sv. Ivan Rilski“, Sofia, Bulgaria. We conducted a prospective and retrospective analysis which covered the patients with vasculitis who were admitted to the Clinic of Rheumatology over the period 2009-2018. Diagnosis was made based on the classification criteria developed by the American College of Rheumatology (ACR, 1990) and the criteria for classification of the vasculitides according to CHCC $[1,2,8,10]$ (Table 1, 2). In some patients, the diagnosis was confirmed with histopathological diagnosis of vasculitis on biopsy from suitable material according to the particular case - nasal mucosa, bronchoscopy, renal biopsy, skin and muscle biopsy. Laboratory tests were conducted in the clinical and immunological laboratory unit at UMHAT „Sv. Ivan Rilski“, Sofia, Bulgaria. The included tests served to determine disease activity (complete blood count (CBC) with differential count, erythrocyte sedimentation rate (ESR), C-reactive protein (CRP), as well as disease severity and systemic involvement (creatinine, urea, liver enzymes, urine sediment, proteinuria, creatinine clearance). The presence of ANCA was evaluated through indirect immunofluorescence (IIF) of ethanol-fixed neutrophils and confirmed through ELISA for antibodies against proteinase-3 and myeloperoxidase. In most patients, we conducted additional examinations for antinuclear antibodies (ANA) through IIF in HEp-2 cells, ANA immunoblot, antiphospholipid antibodies including anticardiolipin (ACL) screen, anti-beta 2 glycoprotein I (anti-b2GPI) screen and anti-prothrombin screen, rheumatoid factor (RF) in order to exclude another systemic connective tissue disease. Organ involvement was confirmed through suitable instrumental studies: radiographs of paranasal sinuses and chest, computed tomography (CT) of chest, head and abdomen, high-resolution CT of lungs, CT angiography, magnetic resonance imaging (MRI) of head, chest and abdomen, abdominal ultrasound, kidney ultrasound, Doppler sonography of blood vessels, electroneuromyography (ENMG), audiogram, spirometry, lung diffusion capacity, consultations with otorhinolaryngologists, ophthalmologists, pulmonologists, nephrologists, neurologists.
Table 2. Vasculitis classification criteria (ACR, 1990)

\begin{tabular}{|c|c|}
\hline DISEASE & CRITERIA \\
\hline $\begin{array}{l}\text { Giant-cell (temporal) arteritis } \\
\text { ( } 3 \text { out of } 5 \text { criteria are } \\
\text { needed to establish the } \\
\text { diagnosis) }\end{array}$ & $\begin{array}{l}\text { Age } \geq 50 \\
\text { New-onset headache } \\
\text { Temporal artery abnormality } \\
\text { Elevated ESR } \\
\text { Abnormal temporal artery biopsy }\end{array}$ \\
\hline $\begin{array}{l}\text { Takayasu arteritis } \\
\text { ( } 3 \text { out of } 6 \text { criteria) }\end{array}$ & $\begin{array}{l}\text { Age } \leq 40 \\
\text { Claudication of extremities } \\
\text { Decreased brachial artery pulse } \\
\text { Blood pressure difference between the two } \\
\text { arms }>10 \mathrm{~mm} \mathrm{Hg} \\
\text { Bruit over subclavian arteries or aorta } \\
\text { Arteriogram abnormality }\end{array}$ \\
\hline $\begin{array}{l}\text { PAN } \\
\text { ( } 3 \text { out of } 10 \text { criteria) }\end{array}$ & $\begin{array}{l}\text { Weight loss } \geq 4 \mathrm{~kg} \\
\text { Livedo reticularis } \\
\text { Testicular pain or tenderness } \\
\text { Myalgia, weakness or leg tenderness } \\
\text { Mononeuropathy or polyneuropathy } \\
\text { Diastolic BP }>90 \mathrm{~mm} \mathrm{Hg} \\
\text { Elevated urea or creatinine } \\
\text { Hepatitis B virus } \\
\text { Arteriogram abnormality } \\
\text { Biopsy of small or medium-sized artery } \\
\text { containing polymorphonuclear cells }\end{array}$ \\
\hline $\begin{array}{l}\text { Wegener's granulomatosis } \\
\text { (2out of } 4 \text { criteria) }\end{array}$ & $\begin{array}{l}\text { Nasal or oral inflammation } \\
\text { Chest X-ray changes } \\
\text { Abnormal urinary sediment } \\
\text { Granulomatous inflammation on biopsy }\end{array}$ \\
\hline $\begin{array}{l}\text { Churg-Strauss syndrome } \\
\text { ( } 4 \text { out of } 6 \text { criteria) }\end{array}$ & $\begin{array}{l}\text { Asthma } \\
\text { Eosinophilia } \\
\text { Mononeuropathy or polyneuropathy } \\
\text { Pulmonary infiltrates, non-fixed } \\
\text { Paranasal sinuses abnormality } \\
\text { Extravascular eosinophilia }\end{array}$ \\
\hline $\begin{array}{l}\text { Henoch-Schönlein purpura } \\
\text { (2out of } 4 \text { criteria) }\end{array}$ & $\begin{array}{l}\text { Palpable purpura } \\
\text { Age } \leq 20 \\
\text { Abdominal angina } \\
\text { Wall granulocytes on biopsy }\end{array}$ \\
\hline $\begin{array}{l}\text { Hypersensitive vasculitis } \\
\text { (3out of } 5 \text { criteria) }\end{array}$ & $\begin{array}{l}\text { Age } \geq 16 \\
\text { Medication at disease onset } \\
\text { Palpable purpura } \\
\text { Maculopapular rash } \\
\text { Biopsy including arteriole and venule }\end{array}$ \\
\hline
\end{tabular}

When establishing the diagnosis of vasculitis during the course of another systemic connective tissue disease, we used the diagnostic criteria of the American Rheumatism Association (ARA), 1982 for SLE; Mathies, 1983 for systemic sclerosis (SSc); Bohan\&Peter, 1975 for polymyositis (PM); ACR, 1987 for RA.

The diagnosis was established on the basis of detailed history of the illness, physical examination and the conducted clinical, laboratory, immunological, histological and instrumental examinations.

The statistical analysis was made with SPSS 13.0. We conducted a descriptive analysis based 
on groups of one or several characteristic features, summarizing the indices relative share and mean. We also performed a diagnostic analysis to test for statistically significant difference between the empirically calculated relative shares. The obtained results were also confirmed through alternative evaluations of the empirical levels of significance (Clopper-Pearson method), which are independent of the traditional ones based on approximations. In addition, we employed models testing whether a statistically significant difference exists between the means (t-test).

In order to evaluate the level of significance of given empirical characteristic features, we used levels based on the assumptions of the distribution of the tested features. The cut-off value of the level of significance was set at 0.05 , unless another value was explicitly stated. The respective evaluations of the significance of a given empirical characteristic feature in the abovementioned tests were compared to this cut-off value of 0.05 . In case it was lower than 0.05 , the tested effect was considered statistically significant; in case the value was higher than 0.05 , it was not considered statistically significant.

\section{RESULTS}

1. Analysis of the nosological association of the patients with vasculitis in the current rheumatological practice.

In the present study, we analyzed 388 patients with vasculitic manifestations, 137 of whom were male and 251 female, respectively, aged between 17 and 85 .

According to the criteria of ACR (ACR, 1990) and the nomenclature of the vasculitides developed by $\mathrm{CHCC}, 278$ patients had primary vasculitides. 174 of all examined vasculitides were AAV. The most often documented diagnoses other than AAV included hypersensitive vasculitis (59 patients), followed by Takayasu arteritis and PAN (14 patients each). The most rarely diagnosed entities were Buerger's disease and isolated angiitis of CNS. The percentage distribution of patients with primary vasculitides relative to all diagnosed vasculitic syndromes is presented on Table 3, while the distribution of the primary vasculitides in terms of nosological entity is indicated on Figure 1.
Table 3. Percentage distribution of patients with primary vasculitides relative to all diagnosed vasculitic syndromes

\begin{tabular}{|l|r|r|r|r|}
\hline Disease & Number & $\%^{*}$ & Male & Female \\
\hline Takayasu arteritis & 14 & $3.61 \%$ & 1 & 13 \\
\hline Horton disease & 3 & $0.77 \%$ & 0 & 3 \\
\hline PAN & 14 & $3.61 \%$ & 12 & 2 \\
\hline GPA & 101 & $26.03 \%$ & 47 & 54 \\
\hline MPA & 59 & $15.21 \%$ & 21 & 38 \\
\hline CSS & 14 & $3.61 \%$ & 4 & 10 \\
\hline Behçet's disease & 10 & $2.58 \%$ & 6 & 4 \\
\hline Buerger's disease & 2 & $0.52 \%$ & 2 & 0 \\
\hline Hypersensitive vasculitis & 59 & $15.21 \%$ & 27 & 32 \\
\hline Isolated angiitis of CNS & 2 & $0.52 \%$ & 2 & 0 \\
\hline Total & $\mathbf{2 7 8}$ & $\mathbf{7 1 . 6 5 \%}$ & 122 & 156 \\
\hline
\end{tabular}

*Based on 388 examined patients

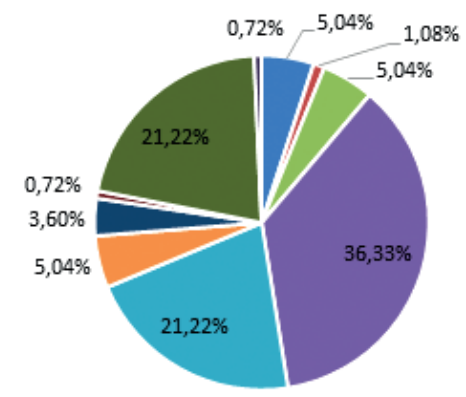

$$
\begin{array}{lll}
\text { - Takayasu arteritis } & \text { - Horton disease } & \text { - PAN } \\
\text { - GPA } & \text { - MPA } & \text { - CSS } \\
\text { - Behçet's disease } & \text { - Buerger's disease } & \text { - Hypersensitive vascultis } \\
\text { - Isolated angiitis of CNS } & &
\end{array}
$$

Fig. 1. Percentage distribution of the primary vasculitides in terms of nosological entity

We observed vasculitic manifestations during the course of another systemic connective tissue disease and/or arthritis in 103 patients $(26.55 \%$ of all vasculitis syndromes). The nosological association could not be determined in8of the vasculitic patients. The highest percentage of vasculitic manifestations were reported in patients with SLE $(43.69 \%$ of all 103 patients), followed by those suffering from SSc $(27.18 \%)$. We noted the relatively high percentage of vasculitic manifestations in patients with rheumatoid polyarthritis ( $11.65 \%$ of the secondary vasculitides). In $16.5 \%$ of patients with secondary vasculitides, we reported an overlap syndrome between several diagnoses, most often between SLE and RA. The nosological entity which most often overlapped with other diagnoses was SLE. In all nosological entities, females were the predominant group. 
The percentage distribution relative to the total number of diagnosed vasculitic syndromes is presented on Table 4, while the distribution of the vasculitic syndromes secondary to other rheumatic diseases is indicated on Figure 2.

Table 4. Percentage distribution relative to the total number of diagnosed vasculitic syndromes

\begin{tabular}{|l|r|r|r|r|}
\hline Disease & Number & $\%^{*}$ & Male & Female \\
\hline SLE & 45 & $11.6 \%$ & 4 & 41 \\
\hline SSc & 28 & $7.22 \%$ & 2 & 26 \\
\hline RA & 12 & $3.09 \%$ & 3 & 9 \\
\hline RA+SSc & 1 & $0.26 \%$ & 0 & 1 \\
\hline SLE+RA & 8 & $2.06 \%$ & 0 & 8 \\
\hline SLE+SSc & 5 & $1.29 \%$ & 1 & 4 \\
\hline SLE+SSc+RA & 2 & $0.52 \%$ & 0 & 2 \\
\hline SLE+ dermatomyositis (DM) & 1 & $0.26 \%$ & 0 & 1 \\
\hline RA+PM & 1 & $0.26 \%$ & 0 & 1 \\
\hline Total & 103 & $\mathbf{2 6 . 5 5 \%}$ & 10 & 93 \\
\hline
\end{tabular}

*Based on 388 examined patients

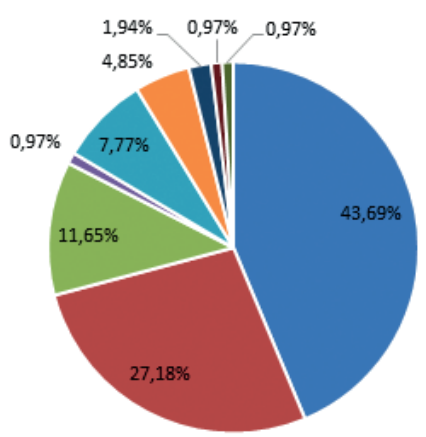

- SLE " SSC | $R A$ " RA+SSC | $S L E+R A ~ \mid-S L E+S S C$ | SLE+SSC+RA | SLE+DM | $R A+P M$

Fig. 2. Percentage distribution of the vasculitic syndromes secondary to other rheumatic diseases

2. Analysis of the nosological association of patients with VN.

In our selected cohort, 147 (37.88\%) of patients had vasculitis with necrotic lesions, while the remaining 241 patients had vasculitis without presence of necrotic lesions. The mean age of the patients who had VN was 40.6 for the male and 44.8 for the female, respectively.

The presence of necrotic lesions over the course of a systemic connective tissue disease and/or arthritis was reported in $70(47.61 \%)$ patients with VN. $24(16.3 \%)$ of patients had been diagnosed with SLE; $28(19.0 \%)$ - with SSc. In the case of these two nosological entities, the difference between the presence of $\mathrm{VN}$ and $\mathrm{V}$ was reported to be statistically significant ( $p=0.0381$ and $p=0.0238$, respectively).
Furthermore, vasculitis often overlaps with various other rheumatic diseases. We talk about overlap rheumatic diseases when we refer to several distinct rheumatic diseases which overlap (clinically and immunologically). In our study, we noted overlap syndromes between a few diseases - SLE and SSc in 5 (1.29\%) patients; SLE and RA in $8(2.06 \%)$ patients; SLE, SSc and RA in $2(0.52 \%)$ patients. Of all 18 patients with overlap diseases, $12(66.67 \%)$ had necrotic lesions; of the patients who had an overlap between SSc and SLE, all (100\%) had necrotic lesions.

VN over the course of a distinct vasculitic syndrome was reported in $45(30.61 \%)$ of the patients with VN, of which $12(8.2 \%)$ had hypersensitive vasculitis of known etiology; $17(11.6 \%)$ had WG; 7 (4.8\%) had MPA, $3(2 \%)$ had CSS; 2 (1.4\%) were diagnosed with PAN; $2(1.4 \%)$ had Buerger's disease, respectively. $30(20.4 \%)$ patients were diagnosed with hypersensitive vasculitis of unknown etiology. The difference between patients with $\mathrm{VN}$ and those with $\mathrm{V}$ across the different vasculitic syndromes was statistically significant in the group of hypersensitive vasculitis of unknown etiology $(p=0.0000)$, where $100 \%$ of patients had necrotic lesions. On the contrary, in patients with WG $(p=0.0000)$, MPA ( $p=$ $0.0000)$, Takayasu arteritis ( $p=0.0167)$, Behçet's disease ( $p=0.0133$ ) necrotic lesions were encountered significantly less often.

In the present study, we did not observe cases of patients with necrotic lesions over the course of temporal arteritis and Behçet's disease. The largest percentage of necrotic lesions as part of distinct vasculitic syndromes was reported in the hypersensitive vasculitides, WG and MPA. It's worth noting that necrotic lesions are most commonly encountered over the course of systemic connective tissue diseases (mainly SSc and SLE) and hypersensitive vasculitides of unknown etiology.

3. Analysis of the nosological association of patients with AAV in the clinical practice.

Based on when the first description of a vasculitis was made, PAN is the oldest necrotizing vasculitis, described by Kussmaul and Meyer in 1866 [12]. WG was described in 1930, MPA in 1940, CSS in 1950. The earliest data on the incidence of WG come from the USA and refer to the period 1976-1980 and show an incidence of 4.0/million yearly [13].

Number, age and sex of the patients. Using the criteria of ACR and CHCC, we found that a total of 174 patients had been treated in the clinic, who had previously been diagnosed with AAV. 101 of these patients had WG, 59 - MPA, 14 - CSS and 5 patients had vasculitis and presence of ANCA but 
Table 5. Comparative characteristic features of VN and $V$ based on their nosological association

\begin{tabular}{|l|r|r|r|r|c|}
\hline Nosological association & $\begin{array}{c}\text { VN } \\
\mathbf{N}=\mathbf{1 4 7}\end{array}$ & \multicolumn{1}{|c|}{$\mathbf{( \% )}$} & $\begin{array}{c}\mathbf{V} \\
\mathbf{N}=\mathbf{2 4 1}\end{array}$ & \multicolumn{1}{c|}{$(\%)$} & $\mathbf{p}$ \\
\hline SLE & 24 & $16.3 \%$ & 21 & $8.7 \%$ & 0.0381 \\
\hline SSc & 28 & $19.0 \%$ & 0 & $0.0 \%$ & 0.0238 \\
\hline SLE+SSc & 5 & $3.4 \%$ & 0 & $0.0 \%$ & 0.0042 \\
\hline SLE+RA & 4 & $2.7 \%$ & 4 & $1.7 \%$ & 0.5034 \\
\hline SLE+DM & 0 & $0.0 \%$ & 1 & $0.4 \%$ & 0.4431 \\
\hline DM & 1 & $0.7 \%$ & 0 & $0.0 \%$ & 0.1632 \\
\hline RA & 6 & $4.1 \%$ & 6 & $2.5 \%$ & 0.3787 \\
\hline RA+PM & 1 & $0.7 \%$ & 0 & $0.0 \%$ & 0.1942 \\
\hline SLE+SSc+RA & 2 & $1.4 \%$ & 0 & $0.0 \%$ & 0.0663 \\
\hline Hypersensitive vasculitis of known etiology & 12 & $8.2 \%$ & 14 & $5.8 \%$ & 0.3599 \\
\hline Hypersensitive vasculitis of unknown etiology & 30 & $20.4 \%$ & 3 & $1.2 \%$ & 0.0000 \\
\hline PAN & 2 & $1.4 \%$ & 12 & $5.0 \%$ & 0.0669 \\
\hline WG & 17 & $11.6 \%$ & 84 & $34.9 \%$ & 0.0000 \\
\hline CSS & 3 & $2.0 \%$ & 11 & $4.6 \%$ & 0.1840 \\
\hline MPA & 7 & $4.8 \%$ & 52 & $21.6 \%$ & 0.0000 \\
\hline Takayasu arteritis & 1 & $0.7 \%$ & 13 & $5.4 \%$ & 0.0167 \\
\hline Temporal arteritis & 1 & $0.7 \%$ & 2 & $0.8 \%$ & 0.2777 \\
\hline Buerger's disease & 2 & $1.4 \%$ & 0 & $0.0 \%$ & 0.0663 \\
\hline Behçet's disease & 0 & $0.0 \%$ & 10 & $4.1 \%$ & 0.0133 \\
\hline Tuberculous aortitis & $0.0 \%$ & 1 & $0.4 \%$ & 0.4431 \\
\hline Isolated angiitis of CNS & $0.0 \%$ & 2 & $0.8 \%$ & 0.2777 \\
\hline
\end{tabular}

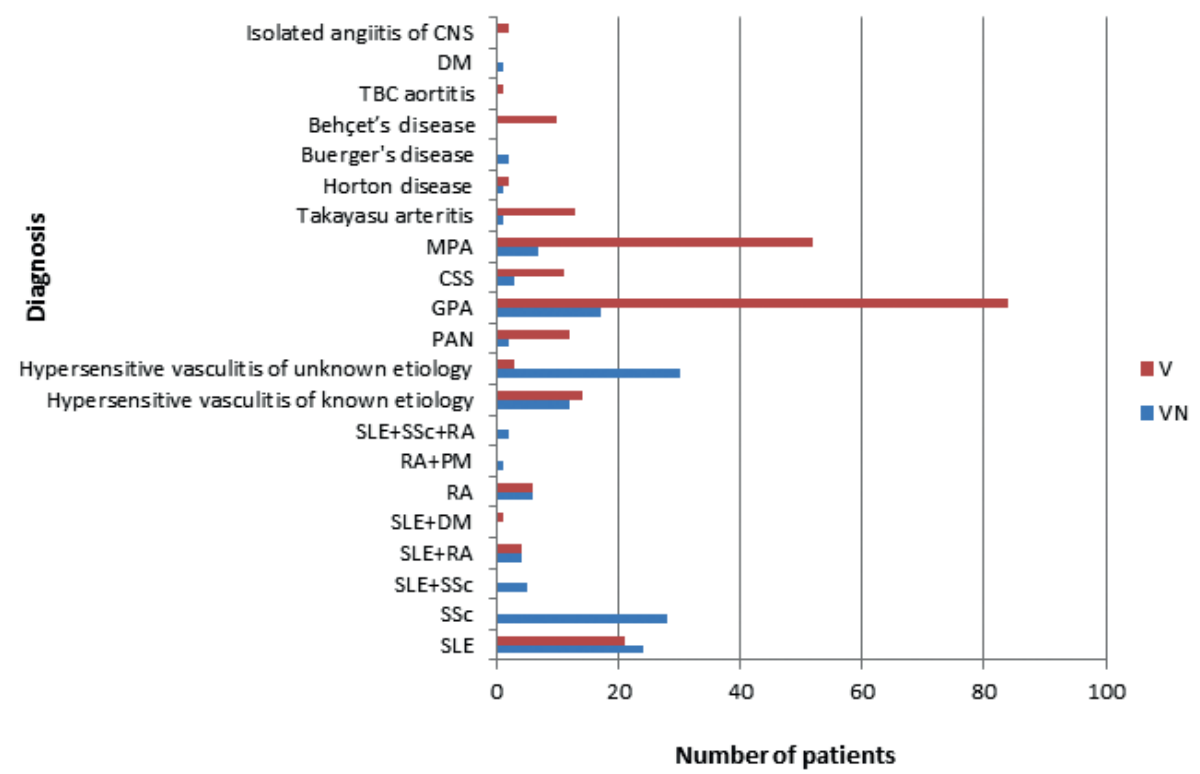

Fig. 3. Comparative characteristic features of $V N$ and $V$ based on nosological association

could not be classified into either of the nosological entities based on the conducted clinical, laboratory, immunological and instrumental examinations. The mean age ( \pm standard error of mean) at which the diagnosis was established was $50.13( \pm 13.40)$ for WG, $52.78( \pm 15.61)$ for patients with MPA and 49.13
$( \pm 15.40)$ for patients suffering from CSS. According to the literature data, the mean age of diagnosis of WG is 50 and remains stable for a period of 15 years according to most epidemiological studies [13]. Patients with MPA tend to be older upon the establishment of the diagnosis as compared to WG. According 
to the European studies, the disease is diagnosed around the age of 60, while in Japan the mean age of diagnosis is 70 [14]. Epidemiological data on CSS are scarcer but again the mean age is around 50 . In our patients, the ratio male:female was 47:54 for WG, 21:38 for MPA and 4:10 for CSS, respectively. Females are the predominant sex in all cases of vasculitis, the difference being most notable in CSS. The mean age of diagnosis is higher in females in cases of WG (52.8/43.5) and MPA (50.2/28.5) and in males in cases of CSS (44.3/63.5). The onset of the disease was observed in a large time frame - between 17 and 85 years of age, but as a whole AAV are encountered in older patients (mean age 50).

Table 6. Demographics of patients with AAV

\begin{tabular}{|l|c|c|c|}
\hline & GPA & MPA & EGPA \\
\hline Number & 101 & 59 & 14 \\
\hline Percentage & $58.05 \%$ & $33.91 \%$ & $8.05 \%$ \\
\hline M:F & $47: 54$ & $21: 38$ & $4: 10$ \\
\hline Age & $50.13(17-76)$ & $52.78(20-85)$ & $49.13(29-70)$ \\
\hline Disease duration & 10.9 months & 8.69 months & 31.25 months \\
\hline
\end{tabular}

Females are the predominant sex in all AAV in the Bulgarian population, with patients suffering from MPA being older when being diagnosed as compared to other AAV.

The mean period between the onset of the first symptoms and the establishment of the diagnosis is longest in EGPA (31.25 months), which is related to the presence of pre-vasculitic stage (asthma preceding the vasculitis). Conversely, the diagnosis is most quickly established in the case of MPA (8.69 months), which is probably due to the rapid onset of severe renal damage, which in turn prompts clinicians to obtain renal biopsy pointing towards the diagnosis of AAV.

\section{Discussion}

More than 380 patients with vasculitic manifestations have been evaluated in the current practice at the Clinic of Rheumatology. Excluding AAV, such manifestations are most often observed in systemic connective tissue diseases and the group of the hypersensitive vasculitides. The most frequent diagnosis featuring vasculitic lesions is SLE, followed by SSc. Most studies report that the incidence of vasculitis in SLE varies between $11 \%$ and 56\% [16, 17, 18, $19,20]$, with cutaneous vasculitis as the predominant type - in $60 \%$ of cases [21, 22]. Vasculitis over the course of SSc is a rarely observed, mostly as part of the limited scleroderma pattern and is associated with the presence of anti-centromere antibodies [23, 24]. Only a few descriptions of cutaneous vasculitis with periungual infarcts and digital ulcerations are reported in the literature in the context of idiopathic inflammatory myopathies $[25,26]$. In our study, we also noted only a small number of such cases.

Perhaps surprisingly, rheumatoid polyarthritis accounts for $3.09 \%$ of cases. It is considered that for a period of one year, $<1 \%$ of patients with rheumatoid polyarthritis will develop vasculitis [27, 28]. In the era of biological disease-modifying therapy and with the achievement of good control over disease activity, the incidence of rheumatoid vasculitis as an extra-articular manifestation of RA has decreased sharply [29].

Of the primary vasculitides, the largest portion of analyzed patients was that of AAV. The highest frequency of them was reported for GPA, followed by MPA and finally EGPA. In $2.87 \%$ of cases, patients with vasculitic manifestations and presence of ANCA could not be classified. The hypersensitive vasculitides and PAN were the next types in terms of frequency. When analyzing the major necrotizing vasculitides (AAV and PAN), it could be noted that PAN is the least frequently encountered type. The incidence of PAN is comparable to that of CSS, which is the most rarely diagnosed AAV, thus confirming the findings of Reinhold-Keller et al. 2005, Mohammad et al. 2009 that PAN is a relative rare disease. The use of $\mathrm{CH}$ CC's classification and definitions in order to distinguish between PAN and MPA has rapidly decreased the incidence of PAN. When using the classification of ACR, the incidence of PAN varies between 6.6 and 8.0 per million; when using $\mathrm{CHCC}$ 's classification, it varies between 0.4 and $2 \%$ [30]. The findings in the present manuscript showed that the incidence of PAN in our patients was lower than that of AAV. Furthermore, they confirmed that the classification of CHCC should be applied when classifying MPA. It is generally considered that AAV do not overlap with other autoimmune rheumatic disease and the literature data on this question are quite scarce. Most often, such overlapping exists with RA, followed by SLE, SSc and Sjogren syndrome [30, 31, 32, 33]. In our patients, AAV were diagnosed together with RA in three patients, with SLE - in one patient and with ankylosing spondylitis - in one patient.

Necrotic lesions are present in various types of vasculitic syndromes, in connective tissue diseases (CTDs) and infections. However, the literature data on this issue are scarce. The classification of the vasculitides according to the existing classification systems is well known, yet it does not give 
an idea of disease severity. On the other hand, the occurrence of necrotic lesions is the most severe form of endothelial dysfunction in the various autoimmune disorders. It is a result of the deposition of immune complexes and subsequent 'cytokine storm' which damage the vascular wall. Our analysis illustrates quite well why SLE and SSc are among the most severe CTDs, as they often progress with severe endothelial dysfunction affecting the smallest blood vessels. Overlap syndromes are likely also related to a higher risk of vascular damage.

The most often established diagnoses in our patients, in which necrotic lesions were encountered, included SSc, SLE and the hypersensitive vasculitides. In $18.5 \%$, VN could not be classified as a distinct nosological entity. The cases of $\mathrm{VN}$ and life-threatening vasculitis were mainly the result of flares of the CTDs - SLE and SSc (33.7\% of patients), with the number of patients with SS and necrotic lesions being significantly higher. According to Lee and Norris (1989), necrotic lesions as a manifestation of lupus vasculitis are usually severe and most often observed in the case of leukocytoclastic vasculitis [34]. Necrotizing vasculitis over the course of SSc is observed in the limited scleroderma pattern and leads to digital gangrene and involvement of the central nervous system (CNS) [35]. It turns out that vasculitis as a manifestation of overlap syndromes was also associated with a higher risk of development of necrotic lesions (in $68.67 \%$ of cases). The hypersensitive vasculitides and those of unknown etiology were the second largest group (26.4\%). Necrotic lesions were diagnosed significantly more often in the group of vasculitides without distinctive nosological association, and they were often the only disease manifestation. It has been suggested that a known or unknown causal agent with tropism towards the vascular wall leads to severe endothelial dysfunction and initiates an inflammatory cascade in the vascular wall without causing the other typical inflammatory changes characterizing the distinct vasculitic syndromes. The major necrotizing vasculitides (WG and MPA) were responsible for $12.6 \%$ of the cases of VN. The occurrence of necrotic lesions in PAN was lower than that in $A A V$, which is related to the caliber of the affected blood vessels - in PAN, the disease involves the medium-sized vessels, while AAV target the small vessels. Most likely, the small blood vessels are more vulnerable and their inflammation could lead to necrosis of the vascular wall more easily.

\section{Conclusion}

AAV were the most often diagnosed vasculitides in the Clinic of Rheumatology. Vasculitic manifestations over the course of CTDs (most often SLE and SSc) were the second most common group. This group also carried the highest risk of development of necrotic lesions. Patients with necrotic lesions without other vasculitic manifestations and without a sufficient number of criteria for diagnosis of systemic vasculitis or CTD also formed a major group. Distinct necrotizing vasculitides of the small and medium-sized blood vessels less often lead to necrotic lesions of the skin and mucous membranes compared to those not belonging to a distinct nosological entity. In order to establish the correct diagnosis and start the suitable treatment, it is of vital importance to recognize the different vasculitic syndromes and their wide differential diagnosis. Most of them respond well to the currently available therapeutic options, especially if the correct diagnosis has been established early.

In addition, we drew the following conclusions:

1. The most frequent diagnosis, in which vasculitic lesions were diagnosed, was SLE, followed by SSc. Perhaps surprisingly, RA was the underlying disease in $11.65 \%$ of cases.

2. The incidence of the different types of AAV was as follows: GPA was the most often diagnosed AAV, followed by MPA and finally EGPA.

3. AAV represented distinct nosological entities and did not overlap with other CTDs.

4. Females constituted the predominant sex in all types of AAV.

5. PAN was diagnosed significantly less often and its incidence was comparable to that of CSS.

6. Life-threatening VN were mainly the result of flares of different CTDs - SLE and SSc $(33.7 \%$ of patients).

7. Necrotic lesions were most often observed in the case of SVV.

8. The major necrotizing vasculitides (WG and MPA) were responsible for $12.6 \%$ of the cases of VN.

9. PAN was the underlying cause in as little as $1.4 \%$ of all cases of $\mathrm{VN}$.

\section{Библиография / References}

1. Larbi T, Hamzaoui S, Abdallah M, et al. Current Classifications. In: Systemic Vasculitis. 1st Ed. L. Hendaoui, A. Stanson, M. Habib Bouhaouala, F. Joffre (Eds.). Berlin, Heidelberg, Springer-Verlag, 2012, 7-13.

2. Gross WL, Trabandt A, Reinhold-Keller E. Diagnosis and evaluation of vasculitis. Rheumatology (Oxford), 2000, 
39(3), 245-252. https://academic.oup.com/rheumatology/article/39/3/245/1783711

3. Abdgawad M. History, Classification and Pathophysiology of Small Vessel Vasculitis, Updates in the Diagnosis and Treatment of Vasculitis, Lazaros I. Sakkas and Christina Katsiari, IntechOpen. https://www.intechopen.com/books/updates-in-the-diagnosis-and-treatment-of-vasculitis/history-classification-and-pathophysiology-of-small-vessel-vasculitis

4. Dunogué B, Pagnoux C, Guillevin L. Churg-Strauss syndrome: clinical symptoms, complementary investigations, prognosis and outcome, and treatment. Semin Respir Crit Care Med, 2011, 32(3), 298-309. https://www.thieme-connect. com/products/ejournals/abstract/10.1055/s-0031-1279826

5. Jennette JC, Falk RJ, Bacon PA, et al. 2012 revised International Chapel Hill Consensus Conference Nomenclature of Vasculitides. Arthritis Rheum, 2013, 65(1), 1-11. https:// onlinelibrary.wiley.com/doi/pdf/10.1002/art.37715

6. Sada KE, Yamamura M, Harigai M, et al. Classification and characteristics of Japanese patients with antineutrophil cytoplasmic antibody-associated vasculitis in a nationwide, prospective, inception cohort study. Arthritis Res Ther, 2014, 16(2), R101. https://arthritis-research.biomedcentral.com/articles/10.1186/ar4550

7. Jennette JC, Falk RJ, Andrassy K, et al. Nomenclature of systemic vasculitides. Proposal of an international consensus conference. Arthritis Rheum, 1994, 37(2), 187-192. https:// onlinelibrary.wiley.com/doi/epdf/10.1002/art.1780370206

8. Basu N, Watts R, Bajema I, et al. EULAR points to consider in the development of classification and diagnostic criteria in systemic vasculitis. Ann Rheum Dis, 2010, 69(10), 17441750. https://ard.bmj.com/content/69/10/1744

9. Fries JF, Hunder GG, Bloch DA, et al. The American College of Rheumatology 1990 criteria for the classification of vasculitis. Summary. Arthritis Rheum, 1990, 33(8), 1135-1136. https:// onlinelibrary.wiley.com/doi/epdf/10.1002/art.1780330812

10. Bruce IN, Bell AL. A comparison of two nomenclature systems for primary system vasculitis. Br J Rheumatol 1997, 36, 453-458. https://academic.oup.com/rheumatology/article/36/4/453/1783341

11. Louis Bridges S, Ball GV. Vasculitis, Oxford, Oxford University Press (P), 2008, 3-21.

12. Koldingsnes W, Nossent $\mathrm{H}$. Epidemiology of ANCA associated vasculitis. Norsk Epidemiologi, 2009, 18(1), 37-48. https:// www.ntnu.no/ojs/index.php/norepid/article/view/62

13. Gibson A, Stamp LK, Chapman PT, et al. The epidemiology of Wegener's granulomatosis and microscopic polyangiitis in a Southern Hemisphere region. Rheumatology (Oxford), 2006, 45(5), 624-628. https://academic.oup.com/rheumatology/article/45/5/624/1788733

14. Hauer HA, Bajema IM, van Houwelingen HC, et al. Renal histology in ANCA-associated vasculitis: differences between diagnostic and serologic subgroups. Kidney Int, 2002, 61(1), 80-89. https://www.kidney-international.org/article/ S0085-2538(15)48154-2/fulltext

15. Ball GV, Fressler BJ, Louis Bridges S. Oxford Textbook of Vasculitis, Oxford, Oxford University Press (P), 2014.

16. Cardinali C, Caproni M, Bernacchi E, et al. The spectrum of cutaneous manifestations in lupus erythematosus--the Italian experience. Lupus, 2000, 9(6), 417-423. https://journals.sagepub.com/doi/10.1191/096120300678828569?u rl_ver = Z39.88-2003\&rfr_id = ori:rid:crossref.org\&rfr_dat = cr_pub\%20\%200pubmed
17. Cieślik P, Hrycek A, Kłuciński P. Vasculopathy and vasculitis in systemic lupus erythematosus. Pol Arch Med Wewn, 2008, 118(1-2), 57-63. https://www.mp.pl/paim/en/node/306/pdf

18. Drenkard C, Villa AR, Reyes E, et al. Vasculitis in systemic lupus erythematosus. Lupus, 1997, 6(3), 235-242. https:// journals.sagepub.com/doi/10.1177/096120339700600304? url_ver = Z39.88-2003\&rfr_id = ori:rid:crossref.org\&rfr_dat = cr_pub\%20\%200pubmed

19. González-Gay MA, García-Porrúa C. Systemic vasculitis in adults in northwestern Spain, 1988-1997. Clinical and epidemiologic aspects. Medicine (Baltimore), 1999, 78(5), 292-308. https://journals.Iww.com/md-journal/Abstract/1999/09000/Systemic_Vasculitis_in_Adults_in_Northwestern.2.aspx

20. Ramos-Casals M, Nardi N, Lagrutta M, et al. Vasculitis in systemic lupus erythematosus: prevalence and clinical characteristics in 670 patients. Medicine (Baltimore), 2006, 85(2), 95-104. https://journals.Iww.com/md-journal/Fulltext/2006/03000/Vasculitis_in_Systemic_Lupus_Erythematosus_.4.aspx

21. Appel GB, Pirani CL, D'Agati V. Renal vascular complications of systemic lupus erythematosus. J Am Soc Nephrol, 1994, 4(8), 1499-1515. https://jasn.asnjournals.org/content/4/8/1499.long

22. Carlson JA, Chen KR. Cutaneous vasculitis update: neutrophilic muscular vessel and eosinophilic, granulomatous, and lymphocytic vasculitis syndromes. Am J Dermatopathol, 2007, 29(1), 32-43. https://journals.Iww.com/amjdermatopathology/Abstract/2007/02000/Cutaneous_Vasculitis_Update_Neutrophilic_Muscular.7.aspx

23. Oddis CV, Eisenbeis $\mathrm{CH}$ Jr, Reidbord HE, et al. Vasculitis in systemic sclerosis: association with Sjögren's syndrome and the CREST syndrome variant. J Rheumatol, 1987, 14(5), 942-948. https://pubmed.ncbi.nlm.nih.gov/3430523/

24. Quéméneur T, Mouthon L, Cacoub P, et al. Systemic vasculitis during the course of systemic sclerosis: report of 12 cases and review of the literature. Medicine (Baltimore), 2013, 92(1), 1-9. https://www.ncbi.nlm.nih.gov/pmc/articles/ PMC5370746/pdf/medi-92-01.pdf

25. Feldman D, Hochberg MC, Zizic TM, et al. Cutaneous vasculitis in adult polymyositis/dermatomyositis. J Rheumatol, 1983, 10(1), 85-89. https://jhu.pure.elsevier.com/en/publications/cutaneous-vasculitis-in-adult-polymyositisdermatomyositis-3

26. Kadoya A, Akahoshi T, Sekiyama N, et al. Cutaneous vasculitis in a patient with dermatomyositis without muscle involvement. Intern Med, 1994, 33(12), 809-812. https://www.jstage. jst.go.jp/article/internalmedicine1992/33/12/33_12_809/_pd$\mathrm{f} /$-char/en

27. Panush RS, Katz P, Longley S, et al. Rheumatoid vasculitis: diagnostic and therapeutic decisions. Clin Rheumatol, 1983, 2(4), 321-330. https://link.springer.com/article/10.1007/ BF02041550

28. Watts RA, Carruthers DM, Symmons DP, et al. The incidence of rheumatoid vasculitis in the Norwich Health Authority. $\mathrm{Br}$ J Rheumatol, 1994, 33(9), 832-833. https://academic.oup. com/rheumatology/article-abstract/33/9/832/1782118?redirectedFrom $=$ fulltext

29. Nyhäll-Wåhlin BM, Petersson IF, Jacobsson C, et al. Extra-articular manifestations in a community-based sample of patients with rheumatoid arthritis: incidence and relationship to treatment with TNF inhibitors. Scand J Rheumatol, 2012, 
41(6), 434-437. https://www.tandfonline.com/doi/full/10.3109 /03009742.2012.695803

30. Hervier B, Hamidou M, Haroche J, et al. Systemic lupus erythematosus associated with ANCA-associated vasculitis: an overlapping syndrome?. Rheumatol Int, 2012, 32(10), 3285-3290. https://link.springer.com/article/10.1007\%2Fs00296-011-2055-z

31. Curtiss P, Liebman T, Khorolsky C, et al. Systemic lupus erythematosus and antineutrophil cytoplasmic antibody-associated vasculitis: An emerging overlap syndrome with cutaneous manifestations. JAAD Case Rep, 2018, 4(5), 493-496. https:// www.ncbi.nlm.nih.gov/pmc/articles/PMC6031565/pdf/main.pdf

32. Draibe J, Salama AD. Association of ANCA associated vasculitis and rheumatoid arthritis: a lesser recognized overlap syndrome. Springerplus, 2015, 4, 50. https://www.ncbi.nlm.

Постъпила за печат: 23.09.2020 2.

Адрес за кореспонденция:

Д-р Цветелина Йонева

Клиника по ревматология

УМБАЛ "Св. Ив. Рилски"

ул. "Урвич" 13

1612 София, България

phone: +359 894530609

e-mail: tz_yoneva@abv.bg
nih.gov/pmc/articles/PMC4315802/pdf/40064_2015_Article_835.pdf

33. Martín-Nares E, Zuñiga-Tamayo D, Hinojosa-Azaola A. Prevalence of overlap of antineutrophil cytoplasmic antibody associated vasculitis with systemic autoimmune diseases: an unrecognized example of poliautoimmunity. Clin Rheumatol, 2019, 38(1), 97-106. https://link.springer.com/article/10.1007\%2Fs10067-018-4212-1

34. Lee LA, Norris DA. Mechanisms of cutaneous tissue damage in lupus erythematosus. Immunol Ser, 1989, 46, 359-386. https://europepmc.org/article/med/2488864

35. Herrick AL, Oogarah PK, Freemont AJ, et al. Vasculitis in patients with systemic sclerosis and severe digital ischaemia requiring amputation. Ann Rheum Dis, 1994, 53(5), 323-326. https://ard.bmj.com/content/53/5/323.long

Submitted: 23.09.2020

Correspondence address:

Dr. Tzvetelina Yoneva, MD

Clinic of Rheumatology

UMHAT "Sv. Ivan Rilski"

13 Urvich St.

1612 Sofia, Bulgaria

phone: +359 894530609

e-mail: tz_yoneva@abv.bg 